\title{
Rapid-scan FTIR difference spectroscopy applied to ubiquinone reduction in photosynthetic reaction centers: Role of redox mediators
}

\author{
Alberto Mezzetti ${ }^{\text {a,b,* }}$ \\ ${ }^{a}$ Service de Bioénergétique, Biologie Structurale et Mécanismes, IBiTec-S, CEA-Saclay, Gif-sur-Yvette, \\ France \\ ${ }^{\mathrm{b}}$ LASIR UMR 8516, Université Lille 1, Villeneuve d'Ascq, France
}

\begin{abstract}
Rapid-scan FTIR difference spectroscopy was used to investigate light-induced reduction of the ubiquinone $\mathrm{Q}_{\mathrm{B}}$, and the oxidation kinetics of $\mathrm{Q}_{\mathrm{B}}{ }^{-}$and $\mathrm{QH}_{2}$ by external mediators in isolated reaction centers (RCs) from $R$. sphaeroides. As redox mediators, a Ferrocyanide/ $\mathrm{N}, \mathrm{N}, \mathrm{N}^{\prime}, \mathrm{N}^{\prime}$-tetramethyl- $p$-phenylenediamine (TMPD) mixture and an Ascorbate/2,3,5,6-tetramethyl$p$-phenylenediamine (DAD) mixture are compared.

Results show that TMPD ${ }^{\text {red }}$ rapidly reduces the photoproduced $\mathrm{P}_{870}{ }^{+}$primary donor. The process is fast enough to record rapid-scan FTIR spectra devoid of $\mathrm{P}_{870}{ }^{+}$bands down to $260 \mathrm{~K}$. Results show also that TMPD ${ }^{\text {ox }}$ oxidises both $\mathrm{Q}_{\mathrm{B}}{ }^{-}$and $\mathrm{QH}_{2}$ faster than $\mathrm{DAD}^{\mathrm{ox}}$. In particular, $\mathrm{Q}_{\mathrm{B}}{ }^{-}$is oxidised faster than $\mathrm{QH}_{2}$ at all temperatures studied.

Results are discussed in the framework of time-resolved infrared studies on $R$. sphaeroides RCs, showing advantages/drawbacks of the proposed experimental approach.
\end{abstract}

Keywords: Reaction center, redox mediators, TMPD, DAD, rapid-scan FTIR, ubiquinone

\section{Introduction}

The photosynthetic reaction center (RC) from $R$. sphaeroides is one of the most-studied membrane enzymes $[16,17,28,36]$.

The structure of the $R$. sphaeroides $\mathrm{RC}$ has been determined with up to $1.87 \AA$ A resolution [18] leading to a detailed knowledge of the position of pigments, cofactors, amino acids, as well as on their relative orientation and distance. Furthermore, for $R$. sphaeroides site-directed mutagenesis is well established, making it possible to change specific amino acids in the RC: most of the recent data on its molecular mechanism come from site-directed mutants $[26,29,36]$.

In the $R$. sphaeroides $\mathrm{RC}$, absorption of a photon entails an ultrafast charge separation between the primary donor $\mathrm{P}_{870}$ (a special pair of bacteriochlorophyll- $a$ molecules) and the primary acceptor $\mathrm{Q}_{\mathrm{A}}$, a ubiquinone molecule strongly bound to the protein. A second ubiquinone molecule, called $\mathrm{Q}_{\mathrm{B}}$, accepts

\footnotetext{
*Address for correspondence: Alberto Mezzetti, Service de Bioénergétique, Biologie Structurale et Mécanismes, IBiTec-S, Bât 532, CEA-Saclay, 91191 Gif-sur-Yvette cedex, France. Tel.: +33 1 69082633; Fax: +33 1 69088717. E-mail: alberto.mezzetti@libero.it.
} 
two electrons from $Q_{A}$ in two consecutive photochemical events, together with two protons from the cytoplasm. Protons are transferred towards the $\mathrm{Q}_{B}$ site through a pathway formed by protonable amino acid side chains and water molecules $[11,28,29,36]$. The ubiquinol $\mathrm{Q}_{B} \mathrm{H}_{2}$ formed leaves the $\mathrm{RC}$ to diffuse in the membrane and is replaced by a new ubiquinone coming from the membrane. The ubiquinol is then reoxidised by the cytochrome $b_{1}$ complex (another enzyme present in the membrane); the overall effect of this series of reactions is to move $\mathrm{H}^{+}$from the cytoplasm to the periplasm. The formed $\mathrm{H}^{+}$gradient is used to synthesize ATP.

Proton and electron transfer reactions play a key role in bioenergetics [2,31,37]. Unlike most other enzymes, the reactions in photosynthetic RCs can be triggered by short laser pulses. This makes photosynthetic RCs ideal systems to investigate proton and electron transfer reactions.

Infrared (IR) difference spectroscopy has been widely used in photosynthesis [3,6,12,25-27]. $R$. sphaeroides $\mathrm{RC}$ is one of the most studied photosynthetic systems $([8,25,26]$ and references therein). Most investigations have been done using static FTIR difference spectroscopy, leading to the identification of marker bands for cofactors, protein rearrangements and amino acid side chains $[8,25,26]$.

Several time-resolved IR investigations have been performed, with the aim of following directly the mechanism of the photoreaction. Single-wavelength ([14] and references therein), rapid-scan FTIR ([13, 21,35] and references therein) or step-scan FTIR ([13] and references therein) techniques have been used.

Data analysis has proven to be a difficult and controversial task; different approaches have been proposed, such as single wavelength analysis [14,20,22], global fit analysis [32] or multivariate curve resolution $[4,5]$. Part of the difficulties of data analysis come from the intrinsic limitations of time-resolved (FT)IR techniques. ${ }^{1}$ In fact, apart from technical requirements $[19,23,33]$, other aspects have to be taken into account. First, to achieve a reasonable signal-to-noise ratio (SNR), experiments must be repeated hundredths or even thousands of times, i.e. samples have to withstand a large number of flashes. This aspect may become critical as prolonged light exposure leads to sample degradation [4].

A second point comes from the quality of the sample, especially the level of occupancy of the $\mathrm{Q}_{\mathrm{B}}$ site. It is very difficult to achieve a $\sim 100 \%$ occupancy of the site in isolated RCs [1,34]; normally, even using an excess of exogenous ubiquinone, $\mathrm{Q}_{\mathrm{B}}$ is present in its binding pocket in only $\sim 80-90 \%$ of the centers. This means that after a laser flash $\mathrm{a}_{\mathrm{B}}{ }^{-}$state is formed in the majority - but not the totality - of the RCs [20]. The situation can become even more confused after two flashes [20].

A third point concerns the experimental scheme to apply; one can choose to investigate the electron transfer between the quinones while the $\mathrm{RC}$ is in a charge-separated $\left(\mathrm{P}_{870}{ }^{+}-\mathrm{Q}^{-}\right)$state (produced after the flash) or, instead, try to mimic the situation taking place in integral bacteria i.e. to quickly reduce $\mathrm{P}_{870}{ }^{+}$by an external electron donor.

Time-resolved differential FTIR experiments performed while the $\mathrm{RC}$ is in the $\left(\mathrm{P}_{870}{ }^{+}-\mathrm{Q}^{-}\right)$chargeseparated state have the advantage of simplicity (the recombination reaction is internal at the RC). Furthermore, the recovery time being relatively fast, photoreactions can be triggered at a quite high frequency (up to $0.05 \mathrm{~Hz}$ [10]). This approach has been used for rapid-scan and step-scan FTIR experiments [10,13,32].

An alternative approach is to ensure fast reduction of $\mathrm{P}_{870}{ }^{+}$by external chemical mediators. These must be capable of reducing $\mathrm{P}_{870}+$ in the shortest time possible (some milliseconds) so that its reduction

\footnotetext{
${ }^{1}$ In the following, we will focus our attention mainly on laser flash-induced techniques. It is important to note that timeresolved FTIR experiments under and after continuous illumination by a lamp have also been carried out, leading to important results $[4,5,20,22]$. Such experiments are mentioned in the text when necessary but not described in details.
} 
is completed before the beginning of the first scan after the flash. This approach has so far been reported only for rapid-scan FTIR ([13,21] and references therein). Apart from the more complicated mechanism of recovery of the initial state (resulting from several redox reactions), an additional drawback comes from the possible presence in the spectra of contributions coming from the mediators used. On the other hand, such approach allows the very large bands associated with $\mathrm{P}_{870}{ }^{+}$formation [25] to be eliminated, making easier to visualize the smaller bands associated with the $\mathrm{Q}_{\mathrm{A}}{ }^{-} \mathrm{Q}_{\mathrm{B}} \rightarrow \mathrm{Q}_{\mathrm{A}} \mathrm{Q}_{\mathrm{B}}{ }^{-}$reaction.

The external mediator approach becomes mandatory when the second electron transfer between quinones is under study; in fact, in order to have, after a first actinic event, a second photo-induced electron transfer reaction, it is necessary to reduce $\mathrm{P}_{870}{ }^{+}$to $\mathrm{P}_{870}$ so that the latter species can induce a second charge-separation event.

In this paper, this experimental approach has been applied to flash-induced, rapid-scan differential FTIR experiments on the two-photon reduction of $\mathrm{Q}_{\mathrm{B}}$. Attention is focused on the advantages/drawbacks of the two proposed mixtures of redox mediator used in the literature $[13,20,21,23]$.

\section{Materials and methods}

RCs from $R$. sphaeroides were isolated in $15 \mathrm{mM}$ Tris- $\mathrm{HCl}, \mathrm{pH} 8,0.0025 \%$ lauryl dimethylamideN-oxide (LDAO) as described [15]. Samples for FTIR measurements were prepared as described [23]. Brielfly, RCs were deposited on a $\mathrm{CaF}_{2}$ window and dried under argon. Before complete dryness, the $\mathrm{RC}$ film was rehydrated with Tris buffer ( $\mathrm{pH} 7)$.

To maximise the occupancy of the $\mathrm{Q}_{\mathrm{B}}$ site, a fivefold excess of ubiquinone-6 (Sigma) was added to the RC suspension.

To ensure fast reduction of $\mathrm{P}_{870}{ }^{+}$two different mixtures were used, following published procedures [20,21]: (i) ferrocyanide $(250 \mathrm{mM})$ and $\mathrm{N}, \mathrm{N}, \mathrm{N}^{\prime}, \mathrm{N}^{\prime}$-tetramethyl-p-phenylendiamine (TMPD; $50 \mathrm{mM}$ ); (ii) $\mathrm{Na}$ ascorbate $(10 \mathrm{mM})$ and 2,3,5,6-tetramethyl-p-phenylenediamine (DAD; $20 \mathrm{mM})$. A second $\mathrm{CaF}_{2}$ window was used to squeeze the sample, to obtain an absorbance in the amide I region of 0.6-0.9 a.u.

Rapid-scan FTIR measurements were performed as in [20]. A Bruker IFS 88 FTIR spectrometer equipped with a photoconductive MCT-A detector and a temperature-controlled $\mathrm{N}_{2}$ cryostat was used. Photoreactions were triggered by a saturating flash from a frequency-doubled Nd:YAG laser (7 ns, $\sim 20 \mathrm{~mJ}$, Quantel, France). The synchronization between laser firing and interferogram acquisition was checked by an oscilloscope. The distance between the 1 st and the 2 nd flash was set to $73 \mathrm{~ms}$; this experimental scheme not only allowed complete reduction of $\mathrm{P}_{870}{ }^{+}$before the 2 nd flash, but also permitted a spectrum between the two flashes to be recorded.

Depending on redox mediators, different waiting times (30 s-4 min) between cycles were applied to allow a complete relaxation of the system (oxidation of $\mathrm{Q}_{\mathrm{B}}{ }^{-}$and $\mathrm{QH}_{2}$ by redox mediators).

Results from 2000 to 3000 cycles (depending on the experiment) were averaged to improve the SNR.

Difference spectra at various times were calculated as described in [23].

\section{Results}

Time-resolved FTIR difference spectra at $268 \mathrm{~K}$ after two consecutive flashes are shown in Fig. 1. In these experiments ferrocyanide and TMPD were used as external electron donors to reduce $\mathrm{P}_{870}{ }^{+}$ $[20,21]$. Compared to the DAD/ascorbate mixture used in several rapid-scan FTIR studies $[13,22,23]$ the ferrocyanide/TMPD mix provides a series of advantages: (i) faster $\mathrm{P}_{870}{ }^{+}$reduction; (ii) shorter relaxation 


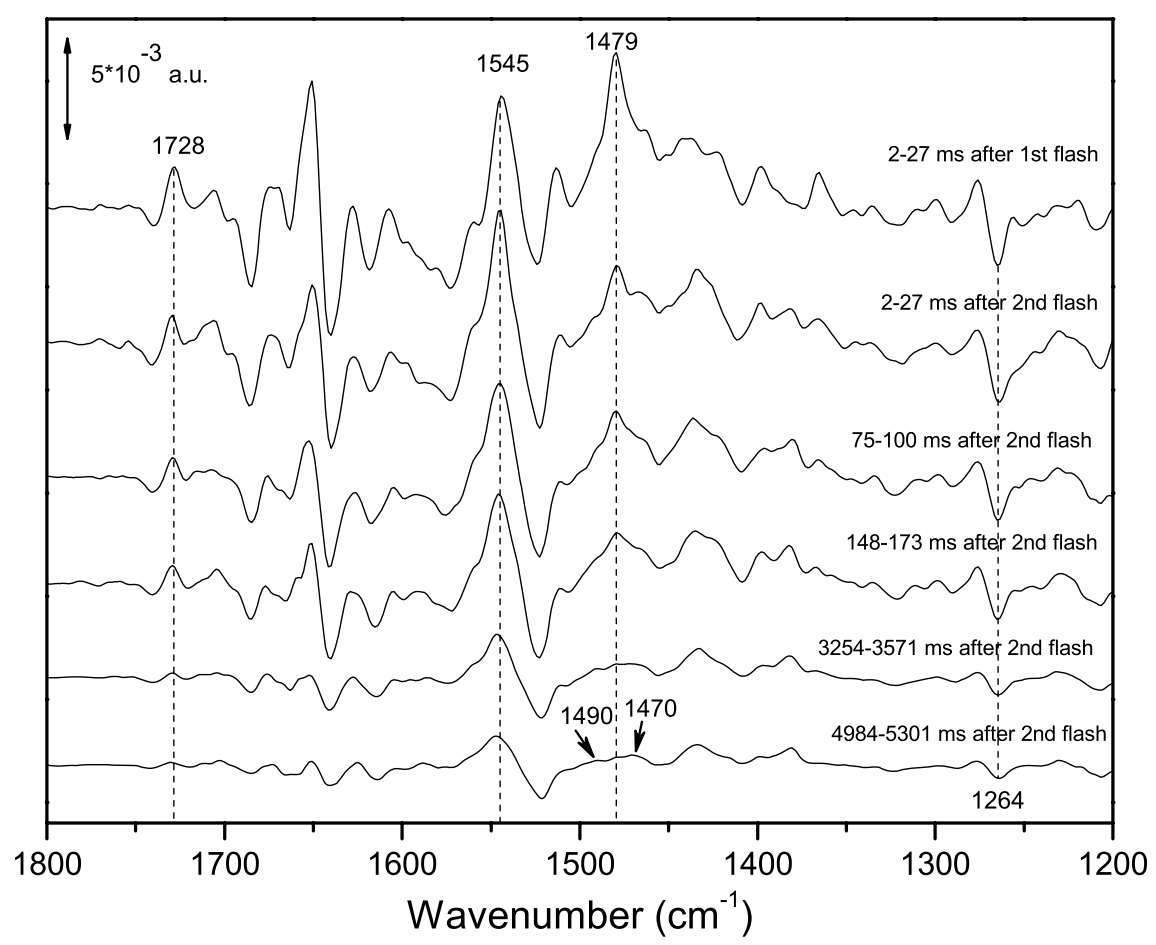

Fig. 1. Time-resolved rapid-scan FTIR difference spectra recorded after two saturating flashes. $T=268 \mathrm{~K}, \mathrm{pH}=7$. Redox mediators: Ferrocyanide/TMPD, see the text for details.

time between measuring cycles; (iii) the possibility of performing measures at lower temperature (down to $260 \mathrm{~K}$ [21]). The main drawback comes from the presence in the spectra of strong contributions from TMPD redox changes (the main positive bands are at 1545 and $1382 \mathrm{~cm}^{-1}$ due to TMPD ${ }^{\text {ox }}$; a strong negative band at $1520 \mathrm{~cm}^{-1}$ is due to TMPD ${ }^{\text {red }}$ ) [9].

The first trace in Fig. 1 corresponds to a spectrum recorded between 2 and $27 \mathrm{~ms}$ after the 1 st flash, but before the 2nd flash. The second trace is recorded between 2 and $27 \mathrm{~ms}$ after the 2 nd flash. The subsequent spectra were recorded at longer delays (see Fig. 1).

Complete and fast reduction of $\mathrm{P}_{870}{ }^{+}$soon after the 1st and the 2nd flashes can be assessed by the absence of the characteristic $1751(+) \mathrm{cm}^{-1}$ band [25] in the corresponding spectra (see traces $\mathrm{a}, \mathrm{b}$ ). Further evidence of $\mathrm{P}_{870}{ }^{+}$reduction is the absence of the characteristic broad electronic transition at $\sim 2500 \mathrm{~cm}^{-1}$ ([25]; not shown).

In the spectra several characteristic bands appear. At $1728 \mathrm{~cm}^{-1}$ a positive band (attributed to the protonated side chain of the Glu-L212 residue and associated to the $\mathrm{Q}_{\mathrm{B}}{ }^{-}$state [26]) is observed after the 1st flash. It is also visible after the 2nd flash but with a weaker and progressively decreasing intensity. In $\sim 1580-1370 \mathrm{~cm}^{-1}$ range spectral contributions from TMPD ${ }^{\mathrm{ox}} / \mathrm{TMPD}^{\text {red }}$ superpose to bands from cofactors and the protein, making difficult a complete and correct spectral interpretation. Nevertheless, some signals in this region remain clearly visible.

A strong positive peak at $1479 \mathrm{~cm}^{-1}$ (due to a $\mathrm{C}-\mathrm{O}$ stretching of $\mathrm{Q}_{\mathrm{B}}{ }^{-}$[8]) is observed in the spectrum recorded after the 1st flash. In spectra recorded at early times after the 2 nd flash such band is still present, albeit weaker in intensity. Such behaviour was observed also in two-flash rapid-scan FTIR experiments at $\mathrm{pH} 8,281 \mathrm{~K}$ using DAD/ascorbate as redox mediators [20]. Another interesting feature is a positive 
band at $\sim 1470 \mathrm{~cm}^{-1}$ (assigned to $\mathrm{QH}_{2}$, tentatively attributed to an aromatic ring vibration [22]) that becomes clearly visible only at later times after the 2 nd flash. At lower wavenumbers, a negative band is visible at $1264 \mathrm{~cm}^{-1}$ (present in all spectra and due to a $\mathrm{C}-\mathrm{O}-\mathrm{CH}_{3}$ mode of the disappearing ubiquinone [20]).

\subsection{Kinetic analysis}

Two-flash rapid-scan FTIR difference spectra (and their possible molecular interpretation) have already been described [20]. Briefly, whereas after the 1st flash an almost pure $\mathrm{Q}_{\mathrm{B}}{ }^{-}$state is produced, after the 2nd flash the difference spectra reflect the formation of $\mathrm{QH}_{2}$ in the majority of $\mathrm{RCs}$, but the formation of a $\mathrm{Q}_{\mathrm{B}}{ }^{-}$state in a significant fraction of RCs (see markers bands for the $\mathrm{Q}_{\mathrm{B}}{ }^{-}$state at $1479(+)$ and $\left.1728(+) \mathrm{cm}^{-1}[20]\right)$.

A previous investigation [20] has shown that this effect can be explained in term of $\mathrm{Q}$ (and $\mathrm{QH}_{2}$ ) exchange equilibrium between pure LDAO micelles and RC-containing LDAO micelles [34]. Detailed mathematical models [34] have shown that one of the consequences of this equilibrium is the extreme difficulty to obtain a $100 \%$ occupancy at the $\mathrm{Q}_{\mathrm{B}}$ site so that after the 1 st flash $\mathrm{Q}_{\mathrm{B}}{ }^{-}$is formed only in $\mathrm{RCs}$ with a ubiquinone molecule in the binding pocket. After the 2nd flash, $\mathrm{QH}_{2}$ is formed in all the $\mathrm{RCs}$ that already have $\mathrm{Q}_{\mathrm{B}}{ }^{-}$whereas in the remaining centers $\mathrm{Q}_{\mathrm{B}}{ }^{-}$is formed [20]. In the present results also the fast oxidation of $\mathrm{Q}_{\mathrm{B}}{ }^{-}$by $\mathrm{TMPD}^{\mathrm{ox}}$ soon after the 1 st flash can have a significant effect by producing in a small fraction of $\mathrm{RCs}$ a $\mathrm{Q}_{\mathrm{B}}$ state immediately before the 2 nd flash (and therefore $\mathrm{Q}_{\mathrm{B}}{ }^{-}$state after the 2nd flash). Such effect can in principle be reduced with a shorter distance between the flash.

One interesting aspect is the temporal spectral evolution after the 2 nd flash. It has already been pointed out that the spectrum recorded between 2-27 ms after the 2nd flash (see Fig. 1) shows some spectral features from an intermediate state (probably partially reflecting $\mathrm{QH}^{-}$formation) [20].

Here we focus our attention on the temporal evolution at longer times, which is caused by oxidation of $\mathrm{Q}_{\mathrm{B}}{ }^{-}$and $\mathrm{QH}_{2}$ by $\mathrm{TMPD}^{\mathrm{ox}}$. This evolution is clearly visible when comparing spectra at early and long times after the 2 nd flash. In spectra recorded some seconds after the 2 nd flash, the $1479(+) \mathrm{cm}^{-1}$ band is no longer present whereas a $1470(+) \mathrm{cm}^{-1}$ band appears (see Fig. 1).

A more precise kinetic analysis can be performed using marker bands: we can easily follow $\mathrm{Q}_{\mathrm{B}}{ }^{-}$ disappearance $\left(1479(+) \mathrm{cm}^{-1}\right.$ band) and Q recovery (the amplitude of the $1264(-) \mathrm{cm}^{-1}$ band indicates the amount of quinones that have been reduced compared to time zero, i.e. system in the dark, before the flashes. The decrease of the amplitude of this band corresponds therefore to oxidation of $\mathrm{Q}_{\mathrm{B}}{ }^{-}$and $\mathrm{QH}_{2}$ to Q).

If we fit the decay of the $1479(+) \mathrm{cm}^{-1}$ band $\left(\mathrm{Q}_{\mathrm{B}}{ }^{-}\right.$state) with a single decaying exponential (although the kinetic behaviour could be more complicated, such a fitting is - at a first approximation - feasible) we obtain a $\tau=1319 \pm 158 \mathrm{~ms}^{2}$

A kinetic analysis can be performed for Q recovery $\left(1264(-) \mathrm{cm}^{-1}\right.$ band). In this case the kinetic behaviour is likely to be more complex, i.e. at least a biexponential, $\mathrm{Q}$ recovery being the result of two different reactions, $\mathrm{Q}_{\mathrm{B}}{ }^{-} \rightarrow \mathrm{Q}$ and $\mathrm{QH}_{2} \rightarrow \mathrm{Q}$. In fact, an exhaustive kinetic model for $\mathrm{Q}$ recovery can be in principle much more complicated, as pointed out in [20]. Nevertheless, the relatively small number of experimental points and the existence in rapid-scan FTIR difference spectra of several sources of error (baseline drift, noise, partial overlap with other spectral contributions, etc.) makes unfeasible a detailed

\footnotetext{
${ }^{2}$ An almost equal value $(\tau=1310 \pm 130 \mathrm{~ms})$ is found when fitting - with a single exponential decay kinetic model $-\mathrm{Q}_{\mathrm{B}}{ }^{-}$ oxidation by TMPD ${ }^{\mathrm{ox}}$ (using the $1479 \mathrm{~cm}^{-1}$ band) after one single saturating flash (data not shown).
} 
Table 1

Kinetics of marker bands at different $T$ using ferrocyanide and TMPD as redox mediators

\begin{tabular}{lccc}
\hline & $1479(+) \mathrm{cm}^{-1}$ & $1264(-) \mathrm{cm}^{-1}$ & $1544(+) \mathrm{cm}^{-1}$ \\
$\left(\mathrm{Q}_{\mathrm{B}}^{-}\right)$ & $(\mathrm{Q})$ & $\tau=1226 \pm 251 \mathrm{~ms}$ \\
\hline $285 \mathrm{~K}$ & $\tau=607 \pm 92 \mathrm{~ms}$ & $\tau=1176 \pm 251 \mathrm{~ms}$ & $\tau=2693 \pm 413 \mathrm{~ms}$ \\
$268 \mathrm{~K}$ & $\tau=1319 \pm 158 \mathrm{~ms}$ & $\tau=2361 \pm 344 \mathrm{~ms}$ & $\tau=4757 \pm 710 \mathrm{~ms}$ \\
$260 \mathrm{~K}$ & $\tau=3907 \pm 382 \mathrm{~ms}$ & $\tau=6568 \pm 809 \mathrm{~ms}$ & $\left.\mathrm{TMP}^{\mathrm{ox}}\right)$ \\
\hline
\end{tabular}

Note: Experiments were carried out at $\mathrm{pH}=7$. Band decays have been fitted as a first-order exponential (see text); the calculated $\tau$ should therefore be taken as a rough estimate of their decay rate.

analysis. A mono-exponential fitting can nevertheless be performed as a first estimate of the kinetics of the process. The $\tau$ obtained is $2361 \pm 344 \mathrm{~ms}$. A simple comparison between the values found for $\mathrm{Q}_{\mathrm{B}}{ }^{-}$ decay and $\mathrm{Q}$ recovery shows that the two processes are not concomitant. This is reasonable, as $\mathrm{Q}$ recovery is given by the two independent chemical reactions $\mathrm{Q}_{\mathrm{B}}{ }^{-} \rightarrow \mathrm{Q}$ and $\mathrm{QH}_{2} \rightarrow \mathrm{Q}$. Unfortunately marker bands for $\mathrm{QH}_{2}$ are not clearly visible in all spectra (they are hidden by $\mathrm{Q}_{\mathrm{B}}{ }^{-}$, protein, $\mathrm{TMPD}^{\mathrm{ox}} / \mathrm{TMPD}^{\text {red }}$ bands) and this does not allow a full detailed kinetic characterization of the global set of redox reactions. $^{3}$

Nevertheless, in the present analysis, the difference between the kinetics of $\mathrm{Q}_{\mathrm{B}}{ }^{-}$disappearance and $\mathrm{Q}$ recovery, along with the qualitative comparison between spectra at early and late times after the 2nd flash (see Fig. 1), shows that $\mathrm{Q}_{\mathrm{B}}{ }^{-}$oxidation is faster than $\mathrm{QH}_{2}$ oxidation. A fast $\mathrm{Q}_{\mathrm{B}}{ }^{-}$oxidation by $\mathrm{TMPD}^{\mathrm{ox}}$ is indeed reported in the literature [24].

Another interesting piece of information comes from the kinetics of TMPD ${ }^{\text {ox }}$ reduction, which can be followed through the $1545(+) \mathrm{cm}^{-1}$ band; using a monoexponential decay, $\tau=2693 \pm 413 \mathrm{~ms}$ is obtained, which is very similar to the value found for $\mathrm{Q}$ recovery. It is worth mentioning that no significant kinetic evolution is observed for the Ferricyanide/Ferrocyanide couple, which has two characteristic bands at 2213 and $2037 \mathrm{~cm}^{-1}$ [7] (data not shown).

The same kinetic scheme $\left(\mathrm{Q}_{\mathrm{B}}{ }^{-}\right.$oxidation faster than $\mathrm{QH}_{2}$ oxidation) seems to apply also at other temperatures $\left(285 \mathrm{~K} ; 260 \mathrm{~K},{ }^{4}\right.$ see Table 1$)$. In addition, preliminary results (not shown) suggest that the kinetic scheme is $\mathrm{pH}$-independent in the $\mathrm{pH} 7-10$ range.

An opposite situation was observed in RCs after continuous illumination [20] using DAD/ascorbate as mediators. In this case the oxidising species $\left(\mathrm{DAD}^{\mathrm{ox}}\right)$ was found to oxidise $\mathrm{QH}_{2}$ faster than $\mathrm{Q}_{\mathrm{B}}{ }^{-}$ (with approximate $\tau$ of 7 and 29 s respectively [20]). Under the considered experimental conditions $E_{\mathrm{m}}$ for $\mathrm{TMPD}^{\mathrm{ox}} / \mathrm{TMPD}^{\text {red }}$ and $\mathrm{DAD}^{\mathrm{ox}} / \mathrm{DAD}^{\text {red }}$ is very similar [30]; therefore the differences in oxidation kinetics may be related to different lipophilicity of TMPD ${ }^{\mathrm{ox}}$ and $\mathrm{DAD}^{\mathrm{ox}}$ and/or to their different capacity to access the $\mathrm{Q}_{\mathrm{B}}{ }^{-}$site and/or to the higher global TMPD concentration compared to global DAD concentration in the sample (50 $\mathrm{mM}$ vs. $20 \mathrm{mM}$ ).

Comparison with data in [20] show that also for $\mathrm{QH}_{2}$ oxidation $\mathrm{TMPD}^{\mathrm{ox}}$ acts faster that $\mathrm{DAD}^{\mathrm{ox}}$ (roughly 4-5 times faster; the lack of a clear $\mathrm{QH}_{2}$ marker band when TMPD is used hampers an exact calculation). The effect is however less pronounced than for $\mathrm{Q}_{\mathrm{B}}{ }^{-}$(its oxidation by $\mathrm{TMPD}^{\mathrm{ox}}$ is $\sim 20$ times faster than oxidation by $\mathrm{DAD}^{\mathrm{ox}}$ ).

\footnotetext{
${ }^{3}$ A more detailed analysis through multivariate curve resolution techniques (in progress) as in [4,5] is in principle capable of overcoming problems arising from overlapping bands, allowing thereby to follow the kinetic evolution of all the involved species.

${ }^{4}$ Time-resolved FTIR spectra recorded in the first scan after the 1 st and 2 nd flash at $250 \mathrm{~K}$ showed strong $\mathrm{P}_{870}{ }^{+}(+) / \mathrm{P}_{870}(-)$ bands implying that $\mathrm{P}_{870}{ }^{+}$reduction is too slow at this temperature.
} 


\subsection{Identification of $\mathrm{QH}_{2}$ bands}

From the description of spectra exposed above it is clear that it is impossible to directly record a FTIR difference spectrum reflecting only $\mathrm{QH}_{2}$ formation, because of contributions, after the 2nd flash, arising from the $\mathrm{Q}_{\mathrm{B}}{ }^{-}$state and from $\mathrm{TMPD}^{\mathrm{ox}} / \mathrm{TMPD}^{\text {red }}$. It is nevertheless possible to calculate an approximate spectrum devoid of bands from the $\mathrm{Q}_{\mathrm{B}}{ }^{-}$state using the strategy proposed in [20]. Indeed, by subtracting (with an appropriate coefficient) a FTIR difference spectrum recorded after a single flash from the averaged spectrum recorded after 2 flashes it is possible to eliminate the spectral features associated with the $\mathrm{Q}_{\mathrm{B}}{ }^{-}$state (see Fig. 2 caption for details).

The result of the subtraction (along with the used experimental spectra) is shown in Fig. 2, trace c. Characteristic bands from $\mathrm{QH}_{2}$ vibrations become visible at $1490(+)$ and $1470(+) \mathrm{cm}^{-1}$.

For completeness, spectra recorded after one (trace d) and two flashes (trace e) using DAD/ascorbate are also shown, together with the spectrum devoid of $\mathrm{Q}_{\mathrm{B}}{ }^{-}$state bands calculated with the same approach as described above (trace $\mathrm{f}$ ).

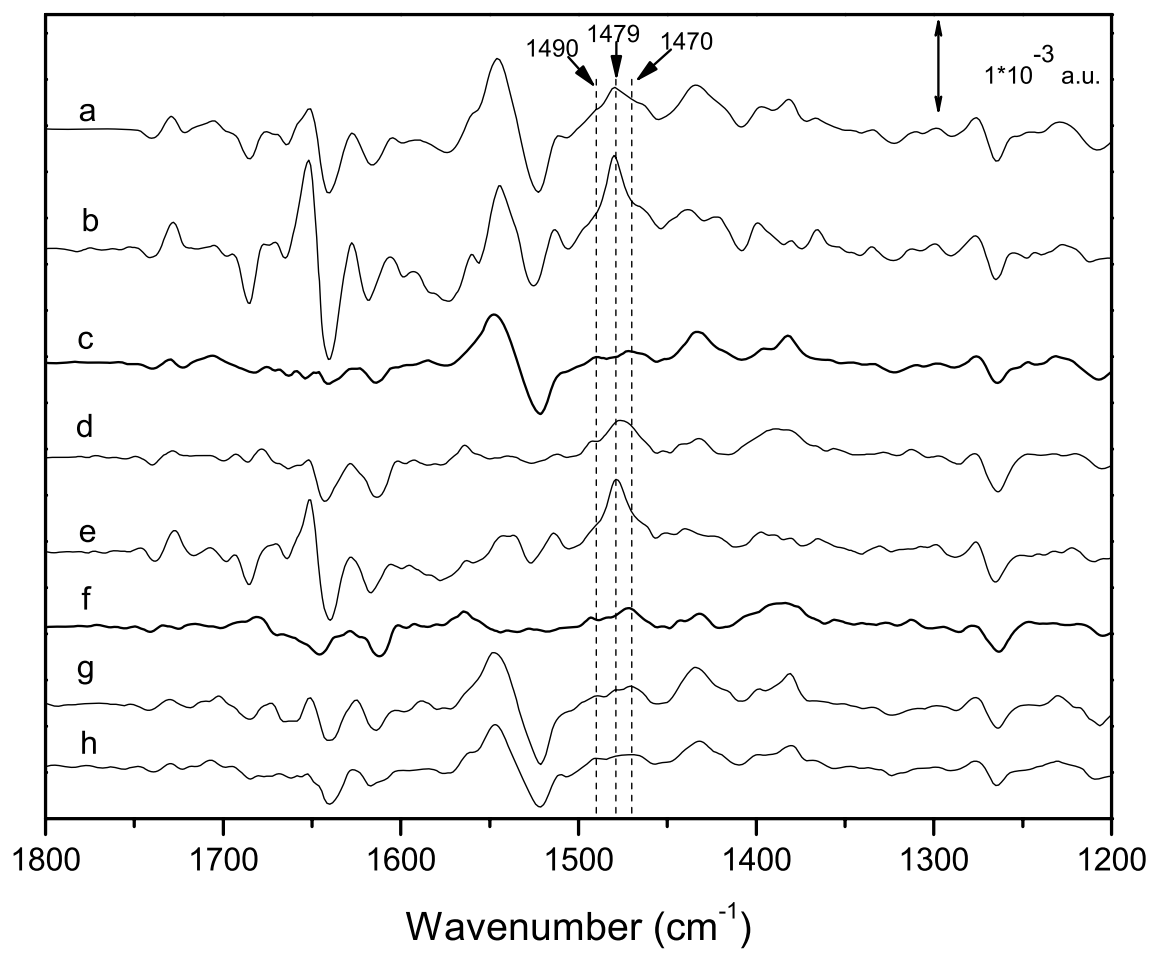

Fig. 2. Identification of $\mathrm{QH}_{2}$ bands in FTIR difference spectra. Trace a: average of spectra recorded between 75 and $976 \mathrm{~ms}$ after the 2nd flash using the ferrocyanide/TMPD mix, $T=268 \mathrm{~K}$. Trace b: average of spectra recorded between 2 and $452 \mathrm{~ms}$ after a single flash, using the ferrocyanide/TMPD mix; $T=268 \mathrm{~K}$. Trace c: reconstructed " $\mathrm{QH}_{2}$ minus Q" spectrum obtained as trace $\mathrm{a}-0.32$ (trace b). Trace d: average of spectra recorded between 75 and $949 \mathrm{~ms}$ after the 2nd flash. Redox mediators: DAD/ascorbate. $T=281 \mathrm{~K}$. Trace e: average of spectra recorded between 2 and $876 \mathrm{~ms}$ after a single flash. Redox mediators: DAD/ascorbate. $T=281 \mathrm{~K}$. Trace f: reconstructed " $\mathrm{QH}_{2}$ minus Q" spectrum obtained as trace $\mathrm{d}-0.36$ (trace e). Trace g: average of spectra recorded between 4984 and $5301 \mathrm{~ms}$ after the 2 nd flash. Redox mediators: ferrocyanide/TMPD. $T=268 \mathrm{~K}$. Trace h: average of spectra recorded between 8850 and $9166 \mathrm{~ms}$ after the 2nd flash. Redox mediators: ferrocyanide/TMPD. $T=260 \mathrm{~K}$. In all experiments $\mathrm{pH}=7$. 
A final remark comes from the kinetic analysis of spectra obtained using Ferrocyanide/ TMPD described above. Indeed, spectra recorded some seconds after the 2nd flash should reflect mainly $\mathrm{QH}_{2}$ formation, because $\mathrm{Q}_{\mathrm{B}}{ }^{-}$decays faster than $\mathrm{QH}_{2}$. The last two traces in Fig. 2 are the average of spectra recorded between 4984 and $5301 \mathrm{~ms}$ at $268 \mathrm{~K}$ (trace g) and the average of spectra recorded between 8850 and $9166 \mathrm{~ms}$ at $260 \mathrm{~K}$ (trace h). Both spectra show characteristic $\mathrm{QH}_{2}$ bands at $1490(+)$ and $1470(+) \mathrm{cm}^{-1}$. Therefore, by using Ferrocyanide and TMPD, it is possible to obtain experimentally (without any spectral subtraction) a $\mathrm{QH}_{2} / \mathrm{Q}$ difference spectrum devoid of spectral contributions from the $\mathrm{Q}_{\mathrm{B}}{ }^{-}$state.

\section{Conclusions}

The rapid-scan FTIR data on $R$. sphaeroides RCs presented here, compared with previous works [20], show that:

(1) $\mathrm{TMPD}^{\mathrm{ox}}$ oxidises $\mathrm{Q}_{\mathrm{B}}{ }^{-}$faster than $\mathrm{QH}_{2}$; such behaviour is observed down to $260 \mathrm{~K}$ and it allows to record FTIR difference spectra reflecting $\mathrm{QH}_{2}$ formation devoid of spectral contributions from $\mathrm{Q}_{\mathrm{B}}{ }^{-}$state.

(2) $\mathrm{TMPD}^{\mathrm{ox}}$ oxidises $\mathrm{QH}_{2}$ faster than $\mathrm{DAD}^{\mathrm{ox}}$ (by a factor of $\sim 4-5$ ) and $\mathrm{Q}_{\mathrm{B}}{ }^{-}$much faster than $\mathrm{DAD}^{\mathrm{ox}}$ (by a factor of $\sim 20$ ).

(3) The presence in the time-resolved FTIR data of TMPD ${ }^{\mathrm{ox}} / \mathrm{TMPD}^{\text {red }}$ marker bands hampers correct visualization of difference spectra reflecting pure RC photochemistry but allows the kinetics of TMPD $^{\text {ox }}$ reduction to be followed. This aspect can be an asset in kinetic analysis; furthermore, as shown recently [7], the presence of redox mediators marker bands can be extremely useful in the comparison of spectra from different samples.

(4) From a methodological viewpoint, fast $\mathrm{Q}_{\mathrm{B}}{ }^{-}$oxidation implies that it is possible to perform 1-flash experiments with high repetition rate (from $\sim 0.02 \mathrm{~Hz}$ at $260 \mathrm{~K}$ to $\sim 0.1 \mathrm{~Hz}$ at $285 \mathrm{~K}$ ). Rapid-scan FTIR difference spectra with a high SNR (comparable to the one of static difference spectra) can therefore be recorded in short measuring times.

\section{Acknowledgements}

I thank Dr. W. Leibl for help in FTIR measurements and useful discussion, and Dr. A.W. Rutherford for stimulating discussion. IBiTec-S (Saclay) is acknowledged for partial financial support.

\section{References}

[1] L. Ambrosone, A. Mallardi, G. Palazzo and G. Venturoli, Phys. Chem. Chem. Phys. 4 (2002), 3071-3077.

[2] D.N. Beratan and S.S. Skourtis, Curr. Opin. Chem. Biol. 2 (1998), 235-243.

[3] C. Berthomieu and R. Hienerwadel, Photosynth. Res. 101 (2009), 157-170.

[4] L. Blanchet, A. Mezzetti, C. Ruckebusch, J.P. Huvenne and A. de Juan, Anal. Bioanal. Chem. 387 (2007), 1863-1873.

[5] L. Blanchet, C. Ruckebusch, A. Mezzetti, J.P. Huvenne and A. de Juan, J. Phys. Chem. B 113 (2009), 6031-6040.

[6] J. Breton, in: Photosystem I: The Light-Driven Plastocyanin: Ferredoxin Oxidoreductase, J.H. Golbeck, ed., Advances in Photosynthesis in Respiration, Vol. 24, Springer, Dordrecht, 2006, pp. 271-289.

[7] J. Breton, Biochemistry 46 (2007), 4459-4465.

[8] J. Breton and E. Nabedryk, Biochim. Biophys. Acta - Bioenergetics 1275 (1996), 84-90. 
[9] J. Breton, J.-R. Burie, C. Berthomieu, D.L. Thibodeau, S. Andrianambinitsoa, D. Dejonghe, G. Berger and E. Nabedryk, in: The Photosynthetic Bacterial Reaction Center II, J. Breton and A. Vermeglio, eds, Plenum Press, New York, 1992, pp. 155-162.

[10] R. Brudler and K. Gerwert, Photosynth. Res. 55 (1998), 261-266.

[11] H. Cheap, S. Bernad, V. Derrien, L. Gerencser, J. Tandori, P. de Oliveira, D.K. Hanson, P. Maroti and P. Sebban, Biochim. Biophys. Acta - Bioenergetics 1787 (2009), 1505-1515.

[12] G. Hastings, in: Photosystem I: The Light-Driven Plastocyanin: Ferredoxin Oxidoreductase, J.H. Golbeck, ed., Advances in Photosynthesis in Respiration, Vol. 24, Springer, Dordrecht, 2006, pp. 301-318.

[13] S. Hermes, J.M. Stachnik, D. Onidas, A. Remy, E. Hofmann and K. Gerwert, Biochemistry 45 (2006), 13741-13749.

[14] R. Hienerwadel, S. Grzybek, C. Fogel, W. Kreutz, M.Y. Okamura, M.L. Paddock, J. Breton, E. Nabedryk and W. Mäntele, Biochemistry 34 (1995), 2832-2843.

[15] R.A. Isaacson, F. Lendzian, E.C. Abresch, W. Lubitz and G. Feher, Biophys. J. 69 (1995), 311-322.

[16] M.R. Jones, Biochem. Soc. Trans. 37 (2009), 400-407.

[17] M.R. Jones, P.K. Fyfe, A.W. Roszak, N.W. Isaacs and R.J. Cogdell, Biochim. Biophys. Acta-Biomembranes 1565 (2002), $206-214$.

[18] J. Koepke, E.M. Krammer, A.R. Klinger, P. Sebban, G.M. Ullmann and G. Fritzsh, J. Mol. Biol. 371 (2007), $396-409$.

[19] W. Mäntele, R. Hienerwadel, F. Lenz, W.J. Riedel, R. Grisar and M. Tacke, Spectroscopy 6 (1991), 25-30.

[20] A. Mezzetti and W. Leibl, Eur. Biophys. J. 34 (2005), 921-936.

[21] A. Mezzetti and W. Leibl, Vibrat. Spectr. 48 (2008), 126-134.

[22] A. Mezzetti, W. Leibl, J. Breton and E. Nabedryk, FEBS Lett. 537 (2003), 161-165.

[23] A. Mezzetti, E. Nabedryk, J. Breton, M.Y. Okamura, M.L. Paddock, G. Giacometti and W. Leibl, Biochim. Biophys. Acta-Bioenergetics 1553 (2002), 320-330.

[24] A.Y. Mulkidjanyan, V.P. Shinkarev, M.I. Verkhovsky and B.S. Kaurov, Biochim. Biophys. Acta-Bioenergetics 849 (1986), $150-161$.

[25] E. Nabedryk, in: Infrared Spectroscopy of Biomolecules, H. Mantsch and D. Chapman, eds, Wiley-Liss Inc., 1996, pp. 3981.

[26] E. Nabedryk and J. Breton, Biochim. Biophys. Acta - Bioenergetics 1777 (2008), 1229-1248.

[27] T. Noguchi, Photosynth. Res. 91 (2007), 59-69.

[28] M.Y. Okamura, M.L. Paddock, M.S. Graige and G. Feher, Biochim. Biophys. Acta-Bioenergetics 1458 (2000), 148-163.

[29] M.L. Paddock, G. Feher and M.Y. Okamura, FEBS Lett. 555 (2003), 45-50.

[30] R.C. Prince, S.J.G. Linkletter and P.L. Dutton, Biochim. Biophys. Acta - Bioenergetics 635 (1981), 132-148.

[31] S.Y. Reece and D.G. Nocera, Ann. Rev. Biochem. 78 (2009), 673-699.

[32] A. Remy and K. Gerwert, Nat. Struct. Biol. 10 (2003), 637-644.

[33] C. Rödig and F. Siebert, in: Handbook of Vibrational Spectroscopy, Vol. 2, J.M. Chalmers and P.R. Griffiths, eds, Wiley, 2002, pp. 641-654.

[34] V.P. Shinkarev and C.A. Wraight, Biophys. J. 72 (1997), 2304-2319.

[35] D.L. Thibodeau, E. Nabedryk, R. Hienerwadel, F. Lenz, W. Mäntele and J. Breton, Biochim. Biophys. Acta-Bioenergetics 1020 (1990), 253-259.

[36] C.A. Wraight, Front. Biosci. 9 (2004), 309-337.

[37] C.A. Wraight, Biochim. Biophys. Acta - Bioenergetics 1757 (2006), 886-912. 


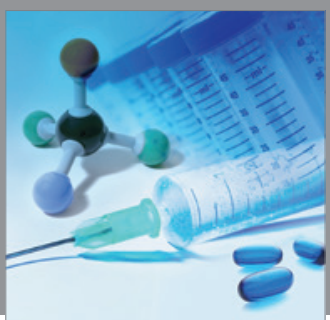

International Journal of

Medicinal Chemistry

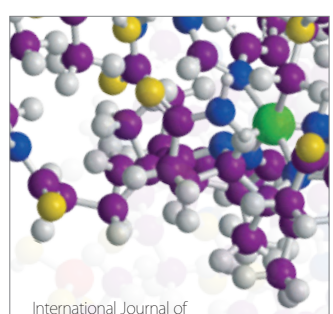

Carbohydrate Chemistry

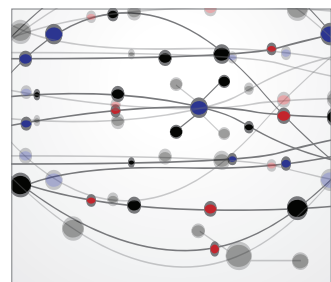

The Scientific World Journal
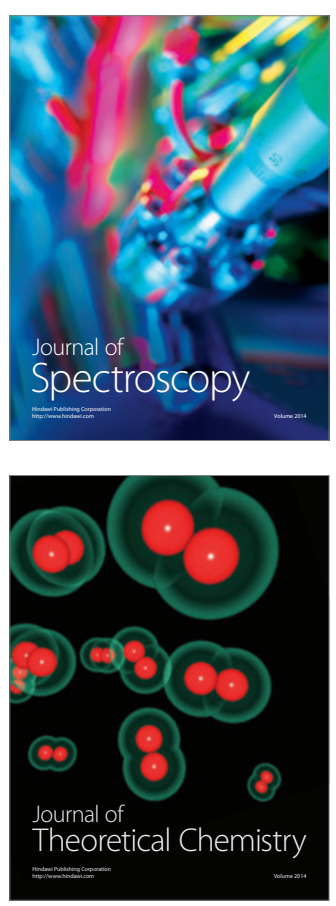
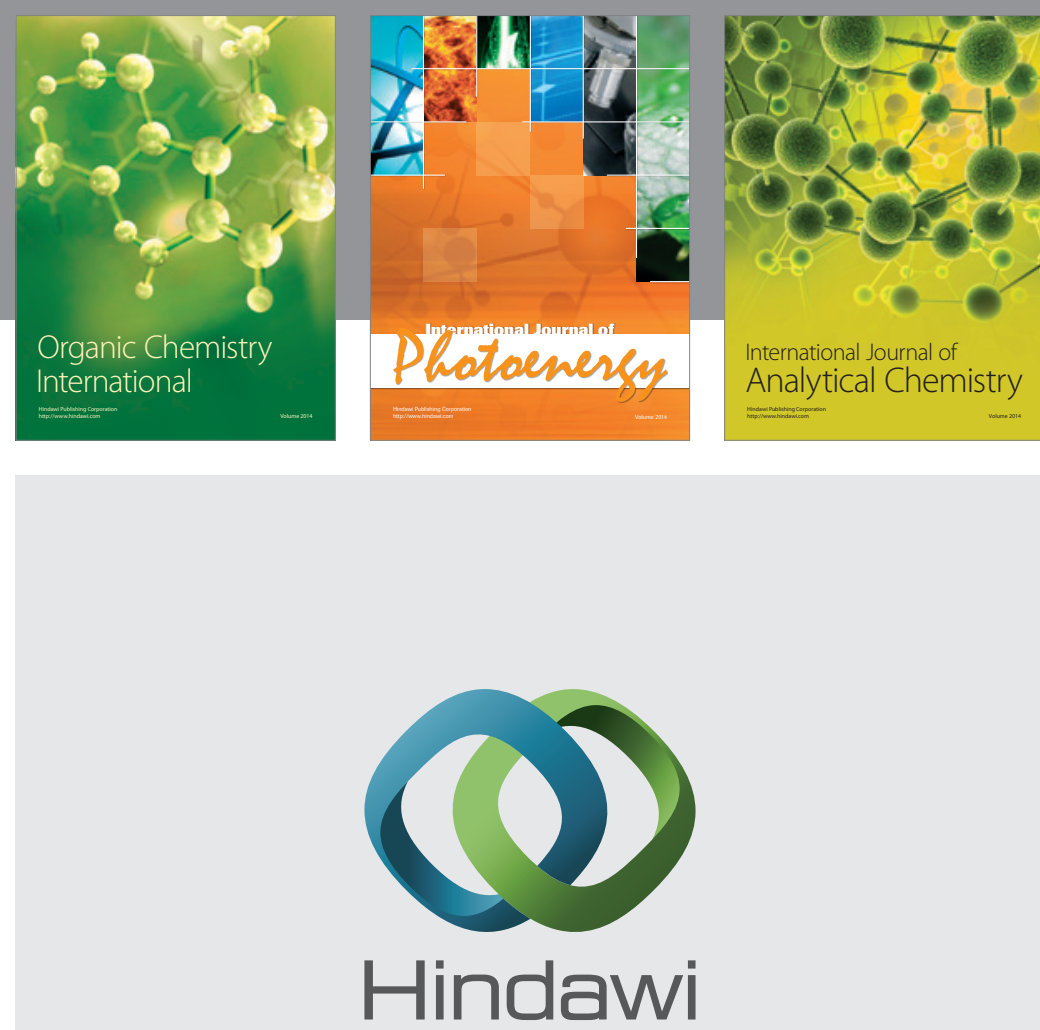

Submit your manuscripts at

http://www.hindawi.com
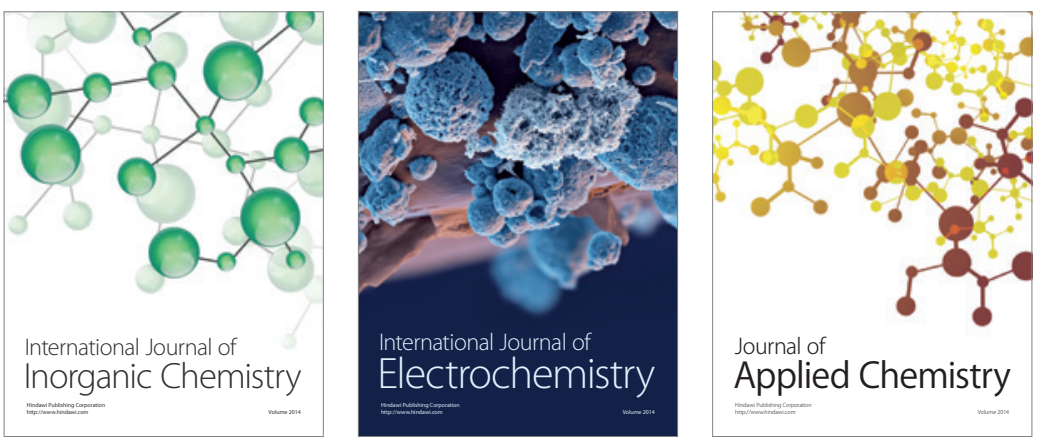

Journal of

Applied Chemistry
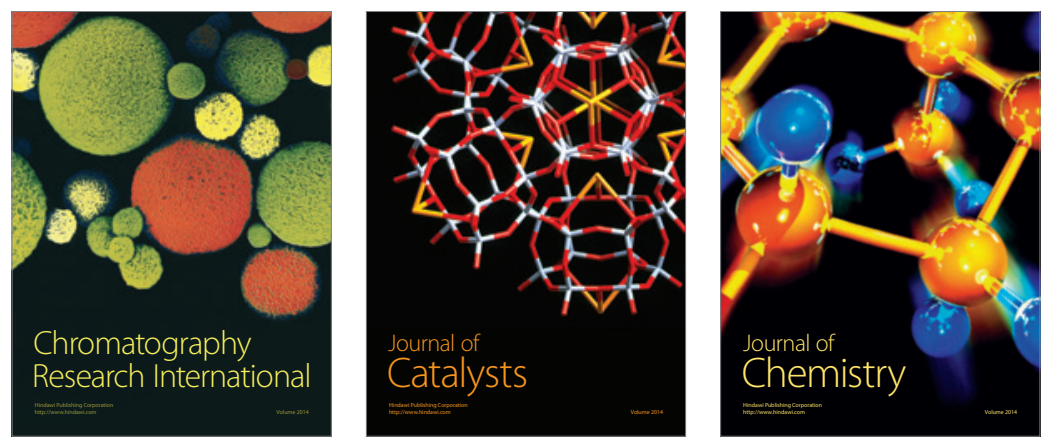
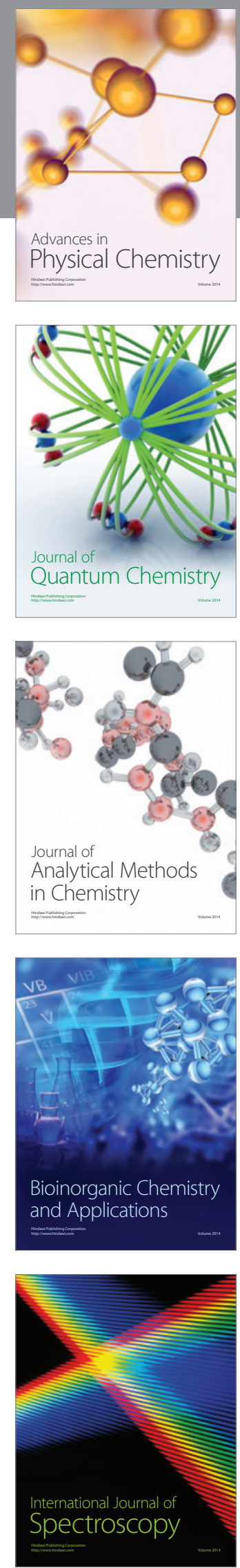